\title{
Pendampingan Usaha Mikro dan Masyarakat Desa Balunijuk dalam Mewujudkan Kampung Halal
}

\section{(Mentoring of Small Business and Community in Balunijuk Village in Realizing Halal Village)}

\author{
Occa Roanisca ${ }^{*}$, Maya Yusnita ${ }^{2}$, Robby Gus Mahardika ${ }^{1}$ \\ ${ }^{1}$ Jurusan Kimia, Fakultas Teknik, Universitas Bangka Belitung, Jl. Kampus Peradaban, Merawang, \\ Bangka, Bangka Belitung 33172. \\ 2 Jurusan Manajemen, Fakultas Ekonomi, Universitas Bangka Belitung, Jl. Kampus Peradaban, Merawang, \\ Bangka, Bangka Belitung 33172. \\ *Penulis korespondensi: occaroanisca@gmail.com \\ Diterima September 2019/Disetujui Januari 2020
}

\begin{abstract}
ABSTRAK
Jaminan kehalalan produk menjadi perhatian dunia khususnya beberapa negara Asia Tenggara. Pemerintah Indonesia melalui UU No. 33 Tahun 2014 mewajibkan produk makanan dan minuman yang beredar di Indonesia harus memiliki sertifikat halal. Merespon program pemerintah pusat tersebut, Pemerintah Provinsi Bangka Belitung telah mengeluarkan Peraturan Daerah tentang Penyelenggaraan Jaminan Pangan Aman dan Halal. Tujuan kegiatan Program Kemitraan Masyarakat (PKM) ini adalah mewujudkan Desa Balunijuk sebagai Kampung Halal. Penentuan tujuan tersebut merupakan hasil kesepakatan antara perangkat Desa Balunijuk dengan pelaku usaha makanan dan minuman. Metode pelaksanaan pada kegiatan ini berupa pembinaan secara langsung terhadap enam mitra binaan untuk memperoleh sertifikat Laik Higiene Sanitasi (HS), dan sosialisasi mengenai halal lifestyle dengan sasaran masyarakat, perangkat desa dan enam usaha warung binaan. Enam usaha warung binaan di Desa Balunijuk telah mendapatkan Sertifikat Laik Higiene Sanitasi (HS). Terbitnya sertifikat HS menunjukkan keseriusan mitra dalam menjaga kebersihan proses produksi, bahan baku dan sanitasi tempat produksi. Sertifikat HS sebagai syarat bagi pelaku usaha untuk mengajukan permohonan sertifikat halal LPPOM MUI di Bangka Belitung. Sebesar 90\% peserta mengerti mengenai materi halal lifestyle, disamping itu peserta merasa perlu untuk menerapkan halal lifestyle terutama dalam pemilihan makanan dan minuman yang akan dikonsumsi karena berdampak pada kesehatan jasmani dan rohani. Hasil dari kegiatan ini merupakan tahapan inisiasi untuk mewujudkan Desa Balunijuk sebagai Kampung Halal.
\end{abstract}

Kata kunci: halal lifestyle, kampung halal, sertifikat higiene sanitasi

\begin{abstract}
Product halal assurance becomes a global concern, particularly in several Southeast Asian countries. The Government of Indonesia through the Law No. 33 of 2014 requires food and beverage products circulating in Indonesia to have halal certificates. Responding to the central government program, the Provincial Government of Bangka Belitung has issued a Regional Regulation on the Implementation of Safe and Halal Food Assurance. The purpose of the Community Partnership Program (PKM) activity was to transform Balunijuk Village become a Halal Village. The determination of these objectives was the result of an agreement between the Balunijuk Village Government and food and beverage businesses. The method of this activity were in the form of direct guidance to the six fostered partners in order to obtaining a Sanitation Hygiene (HS) certificate, and the socialization of halal lifestyle to village community, village staffs and the six fostered business partners. The six fostered business partners have received Sanitation Hygiene Certificate (HS). The issuance of HS certificates showed the seriousness of partners in maintaining the sanitation of the production process, raw materials and the production site. This HS Certificate was required for applying the Halal Certificate of LPPOM MUI in Bangka Belitung. About $90 \%$ of participants understood to halal lifestyle issues. Besides, that participants felt the need to apply halal lifestyle, particularly in selecting food and drinks to be consumed with regard to its impact on physical and spiritual health. The results of this PKM activity were the initiating steps of realizing Balunijuk Village as a Halal Village.
\end{abstract}

Keywords: halal village, halal lifestyle, sanitation hyegene certificate 


\section{PENDAHULUAN}

Jaminan kehalalan produk menjadi perhatian dunia khususnya beberapa negara Asia Tenggara. Indonesia, Malaysia, dan Thailand membentuk kerja sama ekonomi regional dinamakan IMT-GT (Indonesia, Malaysia, Thailand Growth Triangle). Salah satu divisi yang terdapat pada kerja sama IMT-GT adalah divisi halal products bertujuan untuk mengembangkan dan menghasilkan produk yang berstandar bersih dan halal (IMT-GT Implementation Blueprint 2017-2021). Hal tersebut didasari karena meningkatnya kesadaran masyarakat dalam mengonsumsi produk halal (Nusran et al. 2018).

Masyarakat Indonesia sebagian besar beragama Islam, sehingga tuntutan ketersediaan produk halal berupa obat-obatan, makanan, dan barang-barang konsumsi yang lain mendapat sorotan yang serius (Charity 2017). Alasannya dikarenakan mengonsumsi dan menggunakan produk halal merupakan bagian dari ibadah (Nafis 2019). Pemerintah Indonesia memfasilitasi hal tersebut dengan dikeluarkannya UU No.33 Tahun 2014 tentang Jaminan Produk Halal dan mewajibkan semua produk yang beredar di Indonesia harus memiliki sertifikat halal (Mutmainah 2018). Pemerintah Bangka Belitung sangat mendukung program tersebut, tercermin dengan dikeluarkannya Peraturan Daerah No. 16 Tahun 2016 tentang Penyelenggaraan Jaminan Pangan Aman dan Halal dan telah memberikan secara gratis sertifikat halal kepada lebih dari 900 IKM (Industri Kecil dan Menengah) (Sumber data hasil wawancara dengan LPPOM MUI Babel tahun 2019). Program lainnya antara Pemerintah Daerah Bangka Belitung dengan LPPOM MUI Babel pada tahun 2019 adalah merancang pembentukan kampung halal di Bangka Belitung (Republika 2019).

Salah satu upaya yang dapat dilakukan untuk mendukung program pemerintah Provinsi Bangka Belitung dengan memberikan informasi kepada masyarakat pelaku usaha kecil mengenai kriteria proses produksi dan produk yang layak untuk mendapatkan sertifikat laik higiene sanitasi dan halal. Langkah nyata yang dapat dilakukan dengan melakukan pembinaan kepada para pelaku usaha disekitar lingkungan kampus Universitas Bangka Belitung. Melalui Program Kemitraan Masyarakat (PKM) yang didanai oleh Kemenristek Dikti kegiatan pemberdayaan tersebut dapat dilaksanakan, karena tujuan dari program ini, yaitu mampu memberikan kebermanfaatan bagi mitra sasaran. Universitas
Bangka Belitung merupakan satu-satunya universitas yang terdapat di Bangka Belitung dan tergabung dalam kerjasama IMT-GT di bidang pendidikan.

Desa Balunijuk merupakan desa di Kecamatan Merawang Kabupaten Bangka yang langsung berhubungan dengan Universitas Bangka Belitung. Masyarakat Desa Balunijuk sebesar 93,86\% beragama islam (Profil Desa Balunijuk 2017). Sarana pendidikan yang terdapat pada Desa Balunijuk meliputi Universitas Bangka Belitung, Sekolah Polisi Negara (SPN) Lubuk Bunter, Pesantren At-Toybah, Sekolah Dasar Islam Terpadu (SDIT) Al-Mansyur, SD Negeri Balunijuk (Profil Desa Balunijuk 2017). Usaha mikro yang terdapat pada Desa Balunijuk sebanyak 45 usaha yang mengusahakan makanan dan minuman. Tingkat pendidikan terakhir pelaku usaha mikro berpendidikan rendah $\leq$ SMA, hal ini memengaruhi kemampuan manajerial dalam mengelola usaha mikro yang dijalankan (Roanisca et al. 2019).

Kurangnya informasi mengenai prosedur untuk mendapatkan sertifikat laik higiene sanitasi dan halal merupakan faktor utama yang menjadi hambatan untuk mendapatkan sertifikat tersebut. Pelaku usaha kecil di Desa Balunijuk sangat berkeinginan untuk mendapatkan sertifikat tersebut tetapi informasi mengenai kriteria halal dan bersih itu sendiri belum diketahui (Roanisca \& Mahardika 2018). Oleh karena itu sangat diperlukan pembinaan secara langsung kepada beberapa pelaku usaha kecil mengenai prosedur untuk mendapatkan sertifikat tersebut.

Penentuan topik Kampung Halal Balunijuk pada Program Kemitraan Masyarakat (PKM) ini merupakan hasil dari kegiatan Pengabdian Kepada Masyarakat yang dilakukan pada tanggal 26 Juli 2018. Hasil dari kegiatan tersebut adalah masyarakat beserta aparat Desa Balunijuk sepakat menjadikan Desa Balunijuk menjadi Kampung Halal yang didukung juga oleh Dinasdinas Kabupaten Bangka dan LPPOM MUI Bangka Belitung. Langkah awal untuk mewujudkan kampung halal adalah warung makanan dan minuman yang berada pada Desa Balunijuk harus mengantongi sertifikat laik higiene sanitasi dan halal (Adinugraha et al. 2018). Hal tersebut akan ditindaklanjuti dengan cara melakukan pembinaan secara langsung kepada usaha-usaha mikro yang ditetapkan secara langsung berdasarkan kesepakatan bersama dan kesiapan usaha pada kegiatan sosialisasi sebelumnya. Pelaku usaha mikro yang bermitra pada program PKM ini, 
yaitu pelaku usaha mikro yang mengusahakan makanan dan minuman. Usaha mikro yang mendapat pembinaan sebagai inisiator bagi usaha mikro lainnya untuk mendukung program Kampung Halal Balunijuk.

Dukungan masyarakat di sekitar Desa Balunijuk dalam mendukung program Kampung Halal Balunijuk sangat diperlukan. Oleh karena itu, kesadaran masyarakat akan pentingnya mengonsumsi produk halal harus dibangun dan ditingkatkan, karena akan memberikan dampak positif (Nurcahyo \& Hudrasyah 2017). Adanya tuntutan masyarakat akan tersedianya produk yang bersih dan halal akan menjadi motivasi bagi usaha mikro untuk segera mendapatkan sertifikat HS dan halal. Tujuan dari kegiatan Program Kemitraan Masyarakat (PKM) ini, adalah untuk meningkatkan pengetahuan pelaku usaha warung dan masyarakat Desa Balunijuk mengenai produk yang memenuhi standar halal dan bersih, dan melakukan pembinaan kepada pelaku usaha warung untuk mendapatkan sertifikat Laik Higiene Sanitasi (HS) sebagai syarat pengajuan sertifikasi halal LPPOM MUI.

\section{METODE PELAKSANAAN KEGIATAN}

Kegiatan ini dilaksanakan di Desa Balunijuk, Kecamatan Merawang, Kabupaten Bangka dari bulan Juni-Agustus 2019. Sasaran partisipan dibagi dua kelompok, yaitu pelaku usaha warung makanan dan minuman serta masyarakat Desa Balunijuk.

\section{Tahap Persiapan}

Kegiatan yang dilakukan pada tahap persiapan adalah perizinan kepada Pemerintah Desa Balunijuk, penetapan usaha warung yang akan dibina, penetapan jadwal pembinaan untuk mendapatkan sertifikat Laik Higiene Sanitasi (HS) dengan petugas sanitarian dari Puskesmas Kecamatan Baturusa, penetapan jadwal sosialisasi halal lifestyle dengan sasaran masyarakat, perangkat desa, dan pelaku usaha warung dengan auditor LPPOM MUI Bangka Belitung.

\section{Tahapan Pelaksanaan}

Kegiatan pada PKM ini berupa pembinaan secara langsung kepada pelaku usaha warung makanan dan minuman, serta sosialisasi kepada masyarakat, perangkat desa, dan pelaku usaha mengenai halal lifestyle. Pembinaan yang dimaksud mengenai prosedur dan hal-hal yang harus dipenuhi untuk mendapatkan sertifikat HS dan halal agar menghasilkan produk yang aman, bersih, serta halal untuk dikonsumsi. Serangkaian metode pelaksanaan ini dirancang dalam upaya mewujudkan Desa Balunijuk sebagai kampung halal. Kegiatan pertama adalah pembinaan secara langsung mengenai proses produksi dan sanitasi lingkungan yang memenuhi standar laik higiene sanitasi kepada enam usaha warung binaan. Pada kegiatan ini disampaikan juga cara pemilihan bahan baku dan penggunaan bahan aditif sesuai standar bersih dan halal. Akhir kegiatan ini dilakukan monitoring sebagai bentuk pengawasan terhadap perbaikan yang dilakukan oleh usaha warung binaan terhadap temuan/saran yang diberikan. Kegiatan kedua adalah pengambilan sampel makanan dan minuman yang akan dilakukan pengujian di Laboratorium Dinas Kesehatan Kabupaten Bangka sebagai syarat untuk mendapatkan sertifikat laik Higiene Sanitasi (HS). Kegiatan ketiga adalah pengambilan dan penyerahan sertifikat HS kepada enam usaha warung binaan, serta pemasangan spanduk warung binaan menuju bersih dan halal. Kegiatan terakhir adalah sosialiasi mengenai halal lifestyle kepada masyarakat, perangkat desa dan warung binaan Desa Balunijuk. Monitoring berupa penyebaran kuesionar yang berisi tingkat pemahaman peserta terhadap materi yang disampaikan dan dampak yang dirasakan dari kegiatan sosialisasi tersebut.

\section{Tahapan Evaluasi}

Evaluasi dilakukan kepada enam usaha warung binaan untuk mengetahui konsistensi dalam menjalankan aturan yang telah ditetapkan untuk menghasilkan makanan dan minuman yang berstandar bersih dan halal. Evaluasi juga dilakukan pada peserta sosialisasi halal lifestyle dengan metode kuesioner dan wawancara.

\section{HASIL DAN PEMBAHASAN}

\section{Tahapan Persiapan}

Kegiatan ini dilakukan pada bulan Juni 2019. Kegiatan pertama adalah perizinan kepada Kepala Desa Balunijuk sekaligus penetapan warung usaha binaan. Kepala Desa Balunijuk sangat mendukung kegiatan PKM ini dikarenakan keiginan perangkat desa dan masyarakat untuk mewujudkan menjadi Kampung Halal. Selanjutnya penetapan warung usaha binaan dilakukan oleh perangkat desa bagian kasi pemerintahan berdasarkan kesiapan dan lamanya usaha 
warung tersebut telah berjalan. Warung binaan pada PKM ini antara lain;Warung Dapur Pak Cik, Warung Yuk Am, Warun H. Zamhir, Warung Bambu Kuning, Warung Asyik, dan Warung Bik Cek. Selanjutnya, penjadwalan pembinaan kepada warung binaan mengenai cara produksi dan sanitasi lingkungan produksi yang memenuhi standar bersih agar bisa mendapatkan sertifikat laik Higiene Sanitasi (HS). Penjadwalan kegiatan ini dilakukan dengan melakukan kunjungan ke Puskesmas Kecamatan Baturusa Bagian Kesehatan Lingkungan. Bersama dengan petugas sanitarian Puskesmas Baturusa ditentukan jadwal pembinaan pada tanggal 27 Juni 2019 dan tata cara pembinaan yang akan dilakukan sesuai dengan standar puskesmas Baturusa. Kunjungan langsung ke kantor LPPOM MUI Bangka Belitung dalam penjadwalan sosialisasi halal lifestyle dengan narasumber auditor LPPOM MUI Bangka Belitung. Kesepakatannya adalah sosialisasi tersebut dilaksanakan pada tanggal 24 Juli 2019.

\section{Tahapan Pelaksanaan}

- Pembinaan terkait sanitasi dan pemilihan bahan baku berstandar bersih dan halal

Kegiatan ini bertujuan untuk memberikan penjelasan kepada pemilik usaha warung binaan mengenai tata kelola proses produksi dan sanitasi usaha yang memenuhi standar bersih, serta cara pemilihan bahan baku yang memenuhi standar bersih dan halal. Kebersihan dan keamanan suatu produk mendukung kehalalan suatu produk dan merupakan bagian yang tidak dapat dipisahkan (Ambali \& Bakar 2014). Pembinaan terkait sanitasi baik proses produksi maupun lingkungan produksi berstandar bersih diberikan langsung oleh petugas sanitarian dari bagian sanitasi lingkungan dari Puskesmas Baturusa. Petugas sanitarian langsung memberikan arahan mengenai perbaikan yang harus dilakukan dan hal-hal yang harus dihindari agar usaha warung memenuhi kelayakan bersih, seperti dilarang meletakkan sampah terbuka di bawah kompor, peralatan makan harus tertutup, menjaga kebersihan tempat penyimpanan bahan (kulkas), dan tempat produksi. Pembinaan mengenai cara pemilihan bahan baku yang berstandar bersih dan halal disampaikan oleh tim PKM. Bahan baku yang digunakan harus yang sudah memiliki setifikat halal dengan memerhatikan logo halal LPPOM MUI pada kemasan makanan, serta untuk pembelian ayam dan daging sapi harus pada rumah potong hewan yang sudah bersertifikasi halal. Disamping itu, diberikan penjelasan mengenai pentingnya mencuci semua bahan sebelum masuk kedalam tempat penyimpanan (kulkas). Pelaksanaan kegiatan terlihat pada Gambar 1.

Harapan dari kegiatan pembinaan ini adalah diharapkan warung usaha binaan yang telah dibina baik proses produksi maupun sanitasi usaha memenuhi standar bersih dan bisa mendapatkan sertifikat Laik Higiene Sanitasi (HS) dan bersedia menggunakan bahan baku yang telah memiliki logo halal LPPOM MUI.

Hasil dari kegiatan pembinaan ini adalah usaha warung binaan bersedia memenuhi perbaikan terkait proses produksi dan sanitasi tempat produksi. Para pemilik usaha binaan sangat kooperatif dan antusias untuk mendapat sertifikat HS. Disamping itu, mereka juga berkomitmen hanya menggunakan bahan baku yang telah memiliki logo halal LPPOM MUI agar produk yang dihasilkan bersih dan halal. Mereka sampaikan bahwa mereka sangat senang dengan adanya pembinaan ini, dkarenakan banyak halhal yang belum mereka pahami sebelumnya terkait sanitasi dan kehalalan.

\section{- Pengambilan dan pengujian sampel makanan dan minuman}

Kesediaan pemilik warung usaha binaan dalam memenuhi perbaikan dari petugas

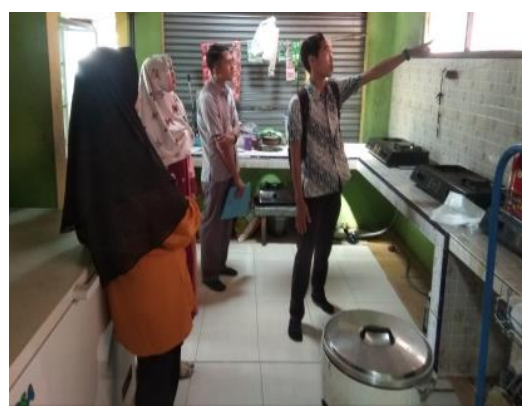

a

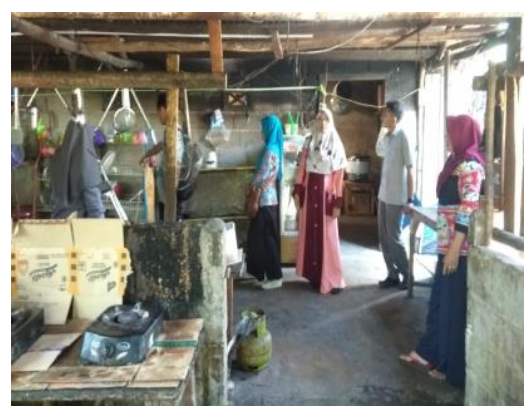

b

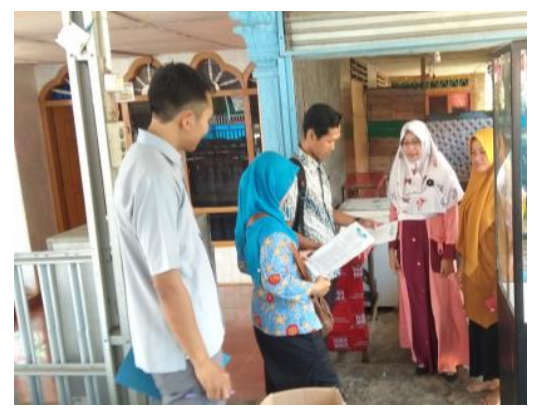

C

Gambar 1 Pembinaan terkait higiene, sanitasi dan pemilihan bahan baku oleh petugas sanitarian dan tim pengabdi. 
sanitarian Puskesmas Baturusa menunjukkan komitmen yang kuat untuk mendapatkan sertifikat HS. Oleh karena itu, tim PKM melanjutkan dengan melakukan pengambilan sampel makanan dan minuman pada enam warung usaha binaan untuk dilakukan pengujian di Laboratorium Dinas Kesehatan Kabupaten Bangka Gambar 2. Pengujian makanan ini bertujuan untuk mengetahui makanan dan minuman yang diproduksi memenuhi standar bersih. Selanjutnya hasil pengujian akan diserahkan kepada Puskesmas Baturusa. Hasil survei petugas sanitarian terhadap perbaikan yang dilakukan oleh enam usaha warung binaan dan pengujian dari laboratorium sebagai dasar pembuatan surat rekomendasi untuk mendapatkan sertifikat HS yang selanjutnya akan diteruskan ke Dinas Kesehatan Bangka (Kemenkes RI 2011)

\section{- Penyerahan sertifikat HS kepada warung binaan}

Sertifikat Laik Higiene Sanitasi merupakan bukti tertulis yang dikeluarkan oleh lembaga berwenang (dinas kesehatan kabupaten/kota) terhadap tataboga yang telah memenuhi persyaratan sesuai dengan peraturan perundangundangan (Kemenkes RI 2011). Disamping itu, terbitnya sertifikat HS sebagai bentuk peng-

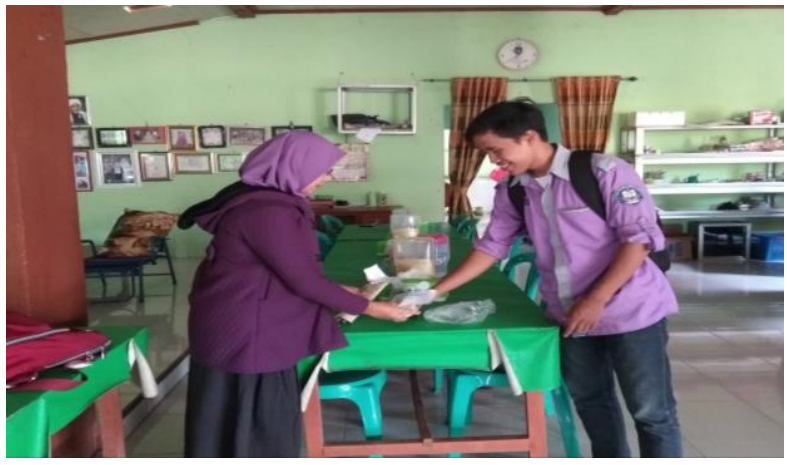

a awasan terhadap higiene dan sanitasi rumah makan agar makanan yang disediakan tidak membahayakan kesehatan manusia (Dakwani 2019). Pengambilan sertifikat HS di Dinas Kesehatan Kabupaten Bangka. Setelah itu, tim PKM langsung menyerahkan sertifikat HS kepada enam usaha warung binaan (Gambar 3), serta pemasangan spanduk warung binaan menuju bersih dan halal. Para pemilik usaha warung binaan sangat berbahagia karena telah memiliki sertifikat HS artinya usaha rumah makan yang mereka usahakan memenuhi standar Higiene dan sanitasi, serta mereka merasa tenang karena usaha warung telah memiliki izin resmi. Disamping itu, dengan dimilikinya sertifikat HS, pemilik warung dapat mengajukan permohonan sertifikat halal ke LPPOM MUI Bangka Belitung.

\section{- Sosialisasi halal lifestyle}

Dalam mewujudkan Desa Balunijuk sebagai kampung halal, diperlukan pengetahuan mengenai pengertian halal, alasan pemilihan produk halal dan pentingnya mengonsumsi makanan dan minuman yang berstandar bersih dan halal (Nofianti \& Rofiqoh 2019). Sasaran pada kegiatan ini adalah masyarakat, perangkat desa dan usaha warung binaan Desa Balunijuk. Kegiatan ini bertujuan untuk memberikan informasi terkait

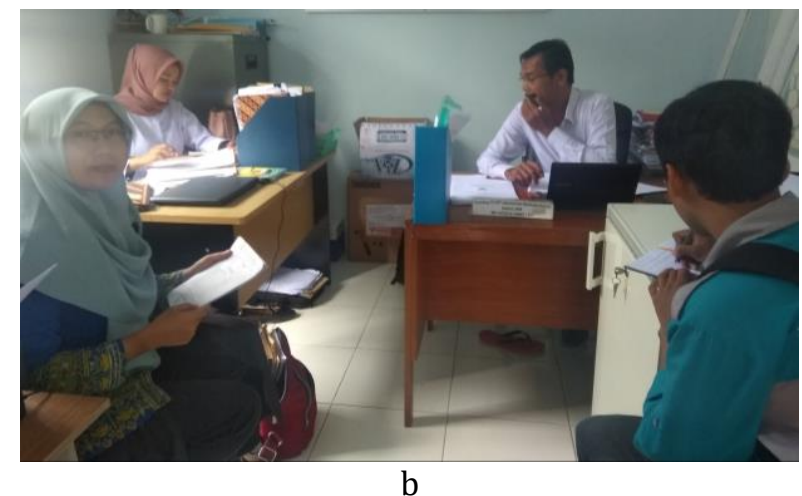

Gambar 2a dan b Pengambilan dan penyerahan sampel makanan ke Laboratorium Kesda Kabupaten Bangka.

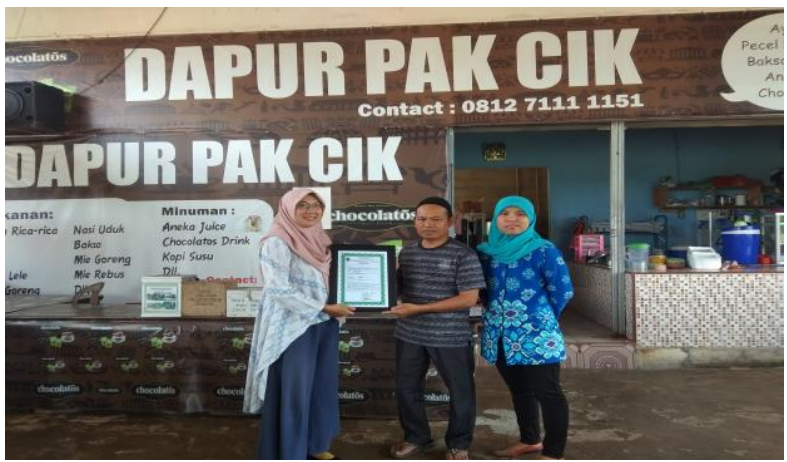

a

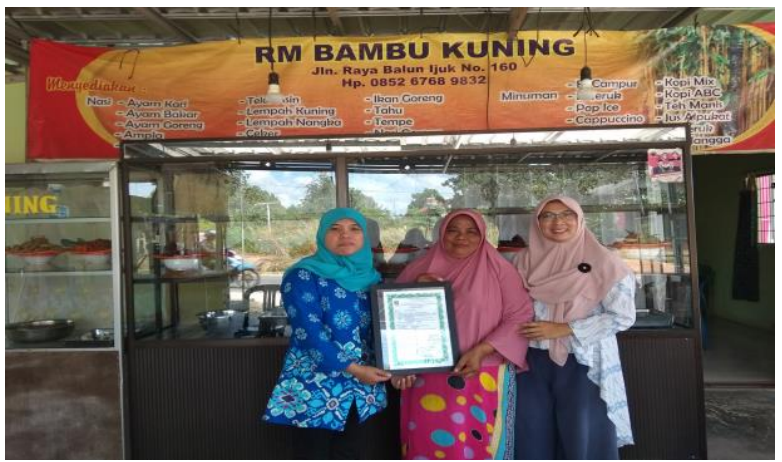

$\mathrm{b}$

Gambar 3 a dan b Penyerahan sertifikat laik higiene sanitasi ke usaha warung binaan. 
halal lifestyle yang disampaikan oleh auditor LPPOM MUI Bangka Belitung. Adanya dukungan yang kuat dari masyarakat dan perangkat desa akan mempermudah terwujudkan kampung halal. Kegiatan sosialisasi berjalan lancar dan kehadiran peserta $100 \%$ sesuai yang ditargetkan Gambar 4. Berdasarakan hasil kuesioner, peserta mengerti mengenai materi yang disampaikan. Tanggapan peserta terhadap materi sosialisasi adalah mereka sangat senang dan berterima kasih dengan adanya kegiatan sosialiasi ini karena membuka dan menambah pengetahuan mereka tentang perlunya kehati-hatian dalam memilih produk yang akan dikonsumsi yang akan berdampak pada kesehatan jasmani dan rohani.

\section{- Tahapan evaluasi}

Pelaksanaan evaluasi dilakukan diakhir kegiatan. Evaluasi dilakukan dalam rangka mengukur tingkat keberhasilan dan keberlanjutan program dalam memberikan dampak perubahan perbaikan pada mitra binaan (Kusnayadi et al. 2019).

Kegiatan pada PKM ini berupa pembinaan kepada enam usaha binaan dan sosialisasi terkait halal lifestyle dengan sasaran masyarakat, perangkat desa, dan enam usaha binaan. Evaluasi terhadap kegiatan pembinaan terkait perolehan

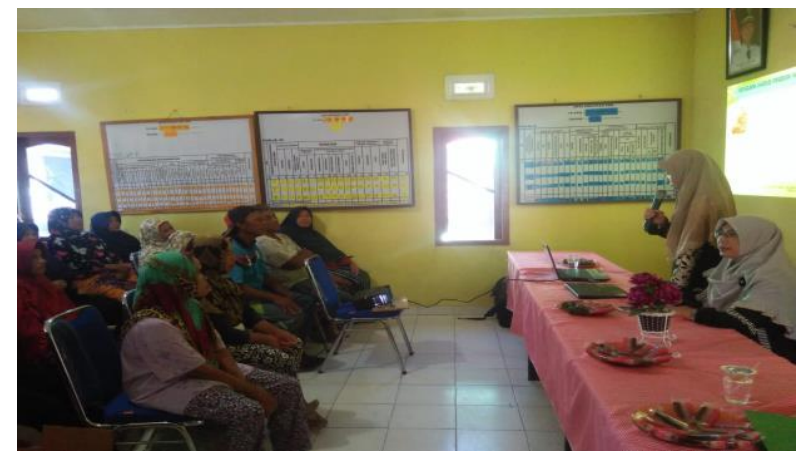

a sertifikat HS dilakukan dengan melihat perbaikan yang telah dilakukan oleh pemilik warung usaha binaan berdasarkan saran dari petugas sanitarian. Konsistensi yang telah ditunjukkan oleh para pemilik usaha warung binaan dalam menjaga kebersihan proses produksi, kebersihan bahan baku, dan sanitasi, sehingga semua usaha warung binaan mendapatkan sertifikat Laik Higiene Sanitasi (HS).

Tingkat pemahaman dan pengetahuan mitra mengenai materi halal lifestyle diukur dengan metode kuesioner, serta wawancara kepada peserta. Berdasarkan hasil kuesioner didapatkan bahwa sebesar $90 \%$ peserta sosialisasi mengerti terhadap materi yang disampaikan dan mampu menggugah kesadaran mereka untuk menerapkan halal lifestyle terutama dalam pemilihan makanan dan minuman yang telah bersertifikat halal LPPOM MUI. Tabel 1 menunjukkan rekapitulasi kuesioner pemahaman peserta mengenai materi sosialisasi halal lifestyle.

\section{SIMPULAN}

Enam usaha warung binaan di Desa balunijuk telah mendapatkan sertifikat laik Higiene Sanitasi (HS) yang difasilitasi oleh program PKM

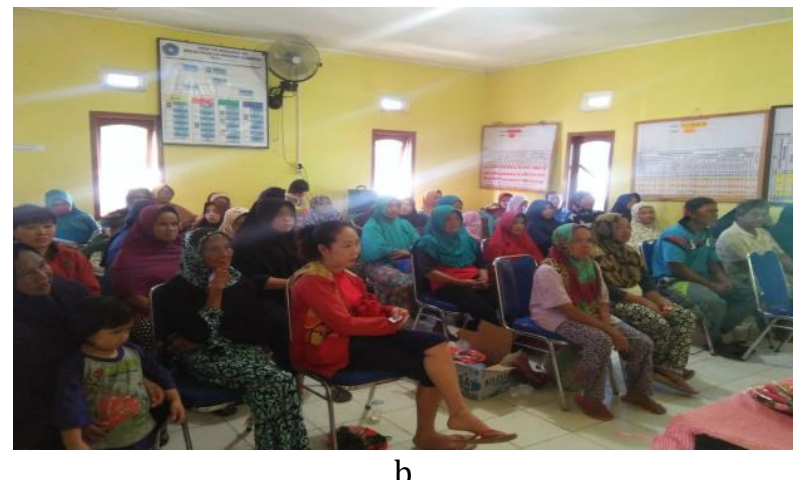

b

Gambar 4 a dan b Sosialisasi Halal Lifestyle oleh auditor LPPOM MUI Bangka Belitung.

Tabel 1 Rekapitulasi kuesioner pemahaman peserta mengenai materi sosialisasi halal lifestyle

\begin{tabular}{|c|c|c|c|c|}
\hline Penyataan & $\begin{array}{c}\text { Sangat setuju } \\
(\%)\end{array}$ & $\begin{array}{c}\text { Setuju } \\
(\%)\end{array}$ & $\begin{array}{c}\text { Kurang setuju } \\
(\%)\end{array}$ & $\begin{array}{c}\text { Sangat tidak } \\
\text { setuju (\%) }\end{array}$ \\
\hline Materi halal lifestyle mudah dimengerti. & 35,00 & 55,00 & 10,00 & 0,00 \\
\hline $\begin{array}{l}\text { Pengetahuan tentang halal lifestyle sangat } \\
\text { diperlukan. }\end{array}$ & 91,67 & 8,33 & 0,00 & 0,00 \\
\hline $\begin{array}{l}\text { Materi sosialisasi halal lifestyle mampu } \\
\text { menggugah kesadaran untuk diterapkan } \\
\text { pada kehidupan sehari-hari. }\end{array}$ & 85,00 & 15,00 & 0,00 & 0,00 \\
\hline $\begin{array}{l}\text { Halal lifestyle perlu diterapkan dalam } \\
\text { kehidupan sehari-hari. }\end{array}$ & 86,67 & 13,33 & 0,00 & 0,00 \\
\hline $\begin{array}{l}\text { Kedepannya hanya membeli produk } \\
\text { makanan dan minuman yang telah memiliki } \\
\text { sertifikat halal resmi. }\end{array}$ & 90,00 & 10,00 & 0,00 & 0,00 \\
\hline
\end{tabular}


Hibah Dikti Ta 2019. Terbitnya sertifikat HS pada usaha warung binaan menunjukkan pemahaman dan keseriusan mitra dalam menjaga kebersihan proses produksi, bahan baku dan sanitasi tempat produksi. Selanjutnya karena telah mengantongi sertifikat HS para pemilik usaha warung binaan dapat mengajukan permohonan sertifikat Halal LPPOM MUI. Sebesar 90\% peserta mengerti mengenai materi halal lifestyle, disamping itu peserta merasa perlu untuk menerapkan halal lifestyle terutama dalam pemilihan makanan dan minuman yang akan dikonsumsi karena berdampak positif pada kesehatan jasmani dan rohani. Hasil kegiatan PKM ini merupakan inisiator untuk mewujudkan Desa Balunijuk sebagai Kampung Halal.

\section{UCAPAN TERIMA KASIH}

Tim pengabdian kepada masyarakat mengucapkan terima kasih kepada Kemenristek Dikti yang telah mendanai Program Kemitraan Masyarakat (PKM) tahun anggaran 2019 sesuai dengan SK Rektor Universitas Bangka Belitung Nomor 1679/UN50/PM/2019.

\section{DAFTAR PUSTAKA}

Adinugraha HH, Sartika M, Kadarningsih A. 2018. Desa Wisata Halal: Konsep Dan Implementasinya Di Indonesia. Human Falah. 5(1): 28-48. https://doi.org/10.21274/ an.2019.5.2.Layout

Ambali AR, Bakar AN. 2014. People's Awareness on Halal Foods and Products: Potential Issues for Policy-Makers. Procedia Social and Behavioral Sciences. 121: 3-25. https:// doi.org/10.1016/j.sbspro.2014.01.1104

Charity ML. 2017. Jaminan Produk Halal di Indonesia. Jurnal Legislasi Indonesia. 14(1): 99-108.

Dakwani T. 2019. Higiene Sanitasi Tempat Pengelolaan Makanan (TPM) di Gudang 100 pada Pelabuhan Laut Tanjung Perak Surabaya Tahun 2018. Jurnal Kesehatan Lingkungan. 11(1): 69-74. https://doi.org/10.20473/ jkl.v11i1.2019.69-74

IMT-GT Implementation Blueprint 2017-2021. [diunduh $2019 \quad$ Sept 10]. Tersediapada:http://ditjenppi.kemendag.go.i d/assets/files/publikasi/doc_20180515_imtgt-blueprint.pdf.

Kemenkes RI 2011 Nomor 1096/MENKES/PER/VI/2011 tentang Higiene Sanitasi Tataboga. [diunduh 2019 Sept 10]. Tersedia pada: jdih.pom.go.id > showpdf.

Kusnayadi H, Merdekawati A, Kusumawardani W. 2019. Pelatihan dan Pendampingan Kelompok Mitra PKM di Desa Leseng, Kecamatan Moyo Hulu, Kabupaten Sumbawa. Agrokreatif Jurnal Ilmiah Pengabdian Kepada Masyarakat. 5(2): 96-102. $\quad$ https://doi.org/10.29244/ agrokreatif.5.2.96-102

Mutmainah L. 2018. The Role of Religiosity, Halal Awareness, Halal Certification, and Food Ingredients on Purchase Intention of Halal Food. Jurnal of Islamic Economics, Finance and Banking. 1(1\&2): 33-50. https://doi.org/ 10.12928/ijiefb.v1i1.284

Nafis MC. 2019. Konsep Halal Dan Thayyib Beserta Implementasinya Di Indonesia. Journal of Halal Product and Research. 2(1):15. https://doi.org/10.20473/jhpr.vol.2issue.1.1-5

Nofianti KA, Rofiqoh SNI. 2019. Kesadaran Dan Logo Halal: Apakah Menentukan Minat Beli? (Studi Pada Praktisi Bisnis Umkm di Gresik). Journal of Halal Product and Research. 2(1): $16-24$.

Nurcahyo A, Hudrasyah H. 2017. The Influence of Halal Awareness, Halal Certification, And Personal Societal Perception Toward Purchase Intention: A Study Of Instant Noodle Consumption of College Student In Bandung. Journal of Business And Management. 6(1): 2131.

Nusran M, Gunawan, Razak M, Numba S, Wekke IS. 2019. Halal Awareness on the Socialization of Halal Certification. Dalam: Prosiding IOP Conference Series: Earth and Environmental Science. Makassar (ID). 25-26 Oktober 2017. https://doi.org/10.1088/1755-1315/175/ 1/012217

Profil Desa Balunijuk. 2017. Hijau Indonesiaku, Kecamatan Merawang, Kabupaten Bangka, Provinsi Kepulauan Bangka Belitung.

Republika. 04 Agustus 2019. Program Kampung Pangan Halal Bertujuan Menguatkan Ekonomi Umat dan warga. diambil dari 
https://babelprov.go.id/content/kampungpangan-halal-menuju-bangka-belitungberkah.

Roanisca O, Mahardika RG. 2018. Pengelolaan Dan Pengembangan Usaha Mikro Di Desa Balunijuk Menjadi Usaha Mikro Kompetitif Halalan Toyyiban. Jurnal Pengabdian Kepada Masyarakat Universitas Bangka Belitung. 5(1): 13-17.
Roanisca 0, Nurohma A, Yusnita M, Mahardika RG. 2019. Pembinaan Tata Kelola Manajemen pada Enam Usaha Warung Makanan dalam Mewujudkan Kampung Pangan Halal Desa Balunijuk. Dalam: Prosiding Seminar Nasional Penelitian \& Pengabdian Pada Masyarakat. Pangkalpinang (ID): 3-4 September 2019. 